\title{
ロックウール培地用水分センサの開発
}

\author{
田中和夫·石黒義昭*·安井秀夫
}

野菜・茶業試験場 $\cdot{ }^{*}$ 矢崎計器株式会社

\section{Development of Moisture Sensor for Rockwool Culture}

\author{
Kazuo Tanaka, Yosiaki Isiguro* and Hideo Yasui** \\ National Research Institute of Vegetables, Ornamental Plants and Tea, \\ Chita, Aichi 470-23, Japan \\ *Yazaki Keiki Co. Ltd, Tenryu, Sizuoka 431-33, Japan \\ **National Research Institute of Vegetables, Ornamental Plants and Tea, \\ Aki, Mie 514-23, Japan
}

\begin{abstract}
This study was carried out in order to develop a moisture sensor for rockwool culture. The moisture sensor consists of a small cylindrical plastic probe $(50 \times 4 \times 4 \mathrm{~mm})$, in which a thermocouple and nichrome wire were buried and isolated from each other by a plastic resin. The probe was placed in the rockwool block, heated by the nichrome wire during $3 \mathrm{~min}$, and the temperature was measured just before and after heating by the thermocouple. When the heat was transmitted to the rockwool block, the difference between the two measured values decreased in proportion to the thermal conductivity which depended directly on the degree of water saturation in the block. This difference was indicated as $\mathrm{mV}$ by the controller. Consequently, the reciprocal of the $\mathrm{mV}$ value showed a close linear correlation with the degree of water saturation. It was essential for standard monitoring in the rockwool culture that the probe remained in close with the lower part of the rockwool mat. The degree of water saturation which was measured automatically gave adequate information for the irrigation control system of rockwool culture.

(Received August 30, 1990)
\end{abstract}

1990 年 8 月 30 日受付

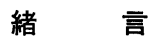

ロックウール栽培では，つねに培地内の気相を確保 し，根への酸素供給を図ると同時に，過度の乾燥による 養水分の偏在化を防ぐために，培地として使用するマッ トの平均飽水度を $50 \%$ 以上に保つ必要がある5 トへの給液方法が適切であれば，マット内の養水分分布 が均一化するとともに, 給液と排液の養分濃度を測定す ることにより，マット内の濃度を推定することができ， 給液量を作物の吸収量より多くすることで，栽培を続け ることができる ${ }^{6)}$. しかし，実際の栽培では，作物の養 水分吸収が天候などにより変化するとともに，マット内 の不均一な養液の移動が, 作物の根の影響だけでなく, マ ット内の繊維密度の不均一およびマットの親水性の局部
的な変化などの影響によっても発生する.また給・排液系 の異常などでマット内の養水分が変動するなど, 上述し た好適な養液濃度および水分状態を維持できない例が多 い. そのため, ロックウール栽培では培地内の養水分の 量や組成を随時測定し, その変動に即応して養水分管理 に必要な修正を加えることが望ましい。

培地の水分量の測定について，いくつかの方法が提案 されているが2 4), 煩雑で実用性に欠けるか, 定量的測 定が困難であるなどの久点がある．本論文ではロックウ 一ル培地用の水分センサの開発を行い, 培地の養水分制 御に使用が可能な結果を得たのでここに報告する.

\section{材料および方法}

\section{1. 水分センサの構造および作製方法}

長さ $4 \mathrm{~cm}$ のテフロンチューブ（ $\phi 2.0 ）$ の中央部に熱 


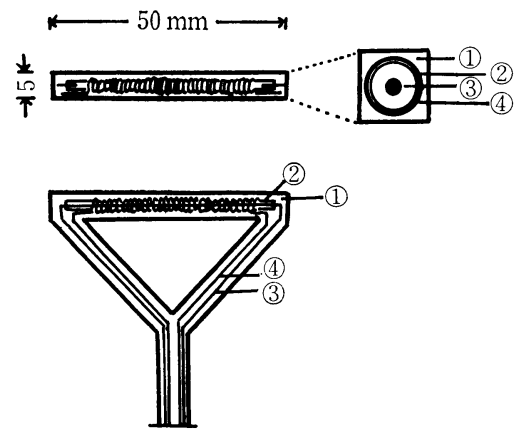

(1): PBT resin (2): Teflon tube

(3) : CC thermocouple (4): Nichrome wire

Fig. 1 Structure of sensor of moisture meter produced for rockwool culture.

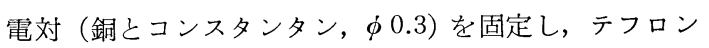

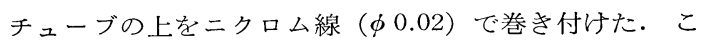
れを PBT (ポリブチルテレスタレイト) 樹脂で断面が $4 \mathrm{~mm}$ 角の棒状に成形した (Fig. 1). 水分測定の場合は ニクロム線に $3 \mathrm{~V}$ の電圧を 1 分間かけ，その加熱前後 の温度を熱電対で測定し，その出力の差をアンプで約 8000 倍に増幅し, ボルト (V) 単位で出力させた.

\section{2. 水分センサの較正および実測}

水分センサとロックウールの水分量との関係をみるた め $10 \times 10 \times 7.5 \mathrm{~cm}$ の育苗用ロックウールブロックの中 央部に水分センサを挿入し, 水分センサの出力值と重量 変化から求めたブロックの平均飽水度との関係を求め た.なお，水分センサの出力值はセンサからロックウー ル培地への熱伝導の大ささに依存するため，センサとロ ックウール培地の接触の程度によって出力值は違ってく る. 実際の栽培ではロックウール培地を変形させること なく, 水分センサーと一定の強さで密着させることが重 要となる. そのため, Fig. 2 に示したように，ロックウ 一ルマットの上面と下面に水分センサを置く方法を検討 した、マットは根を通さない布（ナイロンタフタ, 東洋

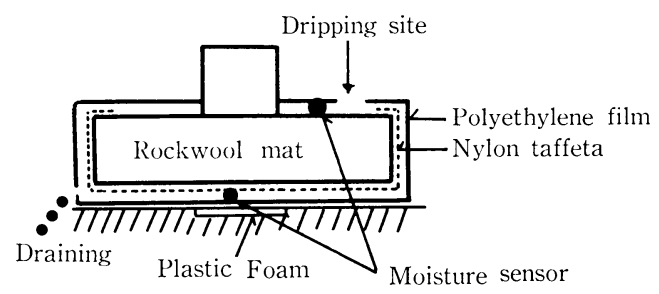

Fig. 2 Rockwool mat wrapped in polyethylene film and position set up of EC sensor and moisture sensor.
紡製）で包み，水分センサに根が回らないようにすると ともに, マットの下面に置く場合は, 水分センサの下に $3 \mathrm{~cm}$ 厚さの発泡スチロールを埋め込んだ. マットの上 面に置く場合は同様に厚さ $3 \mathrm{~cm}$ の発泡スチロールでセ ンサの上からセンサとマットが密着するように押さえ た.この方法でマット（厚さ $7.5 \mathrm{~cm}$, 幅 $30 \mathrm{~cm}$, 長さ $91 \mathrm{~cm})$ の平均飽水度を変えて水分センサの出力值との 関係を求めた. 次に, キュウリを定植後 40 日間栽培し た Fig. 2 の構造のロックウール栽培ベッドで, マット の下面に水分センサを設置し，マットへの給液を停止さ せた後, 30 分ごとに水分センサの出力值を求めた.

\section{結 果}

育苗用ロックウールブロックの中央部に挿入した水分 センサの示す值と，ブロックの平均飽水度との関係を Fig. 3 に示した. 水分センサの周辺に水分量が多いほど 培地への熱伝導が大きくなり，ニクロム線の加熱による センサ部分の温度上昇が小さくなる．このため，加熱前 後の温度差（水分センサの示す值）はロックウールの水 分量とは逆比例する. ロックウールブロックの平均飽水 度が $100 \%$ から 10\% に低下すると，水分センサの出力 值は $1 \mathrm{~V}$ から $2 \mathrm{~V}$ の範囲でほぼ直線的に変化した。次 に，試作した 7 本の水分センサを各ブロックの中央部に 挿入し, おのおののセンサの出力值から求めた值と, 重 量変化から求めた值と比較し，その測定精度をみると 士10\% 以内であった（Fig. 4).ただし，ブロック内へ

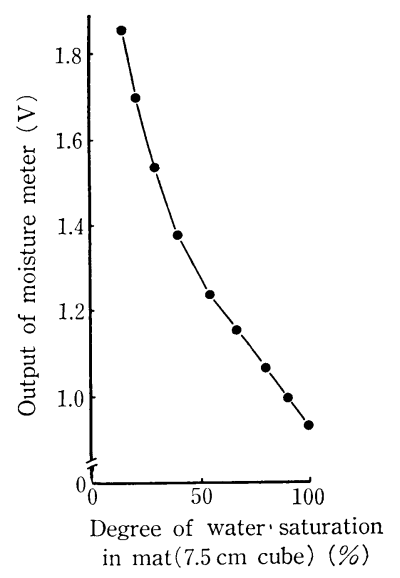

Fig. 3 Output of moisture sensor producted as a trial.

Output of moisture sensor was obtained as follows. Temperature rise by nichrome wire applied $3 \mathrm{~V}$ for $3 \mathrm{~min}$ was measured by CC thermocouple, and it's output was amplified 8000 times.

生物環境調節 (Environ. Control in Biol.) 
のセンサの挿入には注意を必要とし，ロックウールブロ ックと水分センサの接触が不十分であると, 測定精度が 著しく低下した。そこで Fig. 2 に示したように，ロッ クウールマットの下面に水分センサを置く方法で, 水分 センサの出力值を求めた. 作成した 10 本の水分センサ の平均值を Fig. 5 に示した. 水中に入れたときのセン サの出力值は $0.60 \mathrm{~V}$, 空気中での出力值は $3.82 \mathrm{~V}$ であ った. このセンサをマットの下面に設置し, マットの平

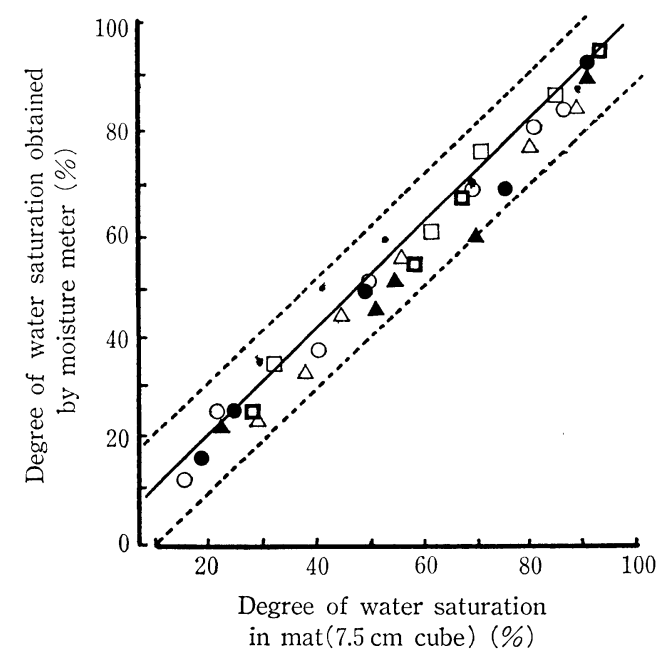

Fig. 4 Accuracy of the measured value obtained by seven moisture sensors.

Same symbol is value obtained by same moisture sensor. Solid line showes a expected value. Dotted lines showes $\pm 10 \%$ range.

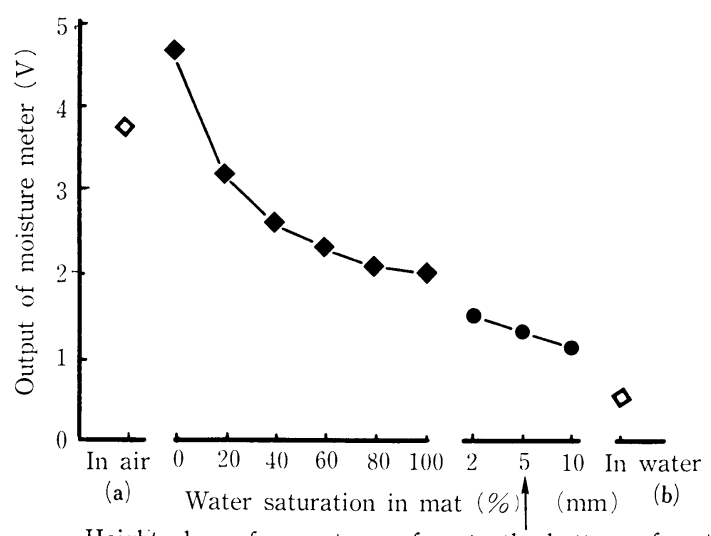

Height above free water surface to the bottom of mat

Fig. 5 Output of moisture sensor set up at bottom of rockwool mat.

(a): Output of moisture sensor in air,

(b): Output of moisture sensor in water.
均飽水度を変化させたときの水分センサの出力值は 95 \%で $2.11 \mathrm{~V}, 80 \%$ で $2.15 \mathrm{~V}, 60 \%$ で $2.39 \mathrm{~V}, 40 \%$ で $2.65 \mathrm{~V}, 20 \%$ で $3.22 \mathrm{~V}, 0 \%$ で $4.65 \mathrm{~V}$ であった. 水分 センサをマットの下面に置いた場合の出力值は, マット の平均飽水度に対して直線的には変化せず, 平均飽水度 の低い領域ではその值の変化が大きく, 逆に平均飽水度 の高い領域での変化が小さくなった. また, 栽培ベッド内 に過剩水がある場合の水分センサの出力值は, 自由水面 の高さが $2 \mathrm{~mm}$ で $1.71 \mathrm{~V}, 5 \mathrm{~mm}$ で $1.36 \mathrm{~V}, 10 \mathrm{~mm}$ で $1.15 \mathrm{~V}$ であった。このように栽培ベッド内に過剩水が ある場合は，過剩水がない場合に比べ明らかにセンサの 出力值が小さくなった.

次に，ロックウールマットの上に置く方法で求めたと きの 10 本の水分センサの平均出力值は, マットの平均 飽水度が $80 \%$ で $2.41 \mathrm{~V}, 60 \%$ で $2.91 \mathrm{~V}, 40 \%$ で $3.33 \mathrm{~V}, 20 \%$ で $3.64 \mathrm{~V}, 0 \%$ で $4.57 \mathrm{~V}$ であった. 栽 培ベッド内に $5 \mathrm{~mm}$ 高さの過剩水がある場合の出力值は $2.28 \mathrm{~V}$ であった：水分センサをマットの上に置いた場 合は, マットの下に置いた場合とは逆に，平均飽水度の 高い領域での出力值の変化が大きくなった。

栽培中のマットの水分量の変化を水分センサで連続的 に計測するため, キュウリを40 日間栽培したロックウ ール栽培ベッドの下面に水分センサを設置し，給液停止 後のマットの水分量の低下に伴う, 水分センサの出力值 の変化を求めた (Fig. 6). 給液停止後, キュウリの蒸散 によりマットの水分量は低下し，それに伴い水分センサ の出力值は上昇した. この上昇速度は最初は緩やかで,

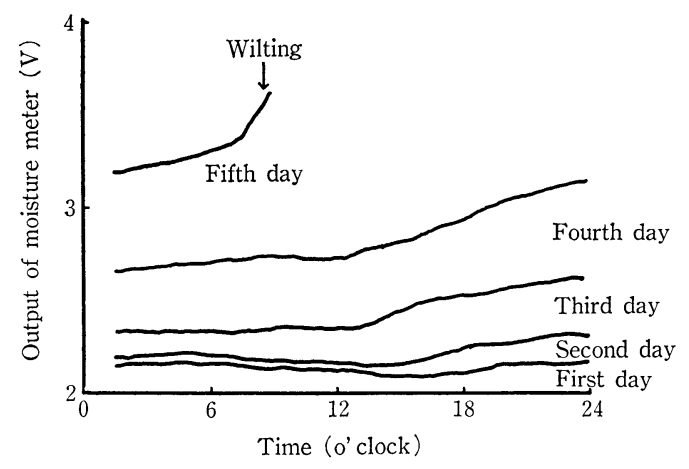

Fig. 6 Change of output of moisture sensor set up at bottom of rockwool mat in cucumber culture after irrigation was stopped.

Two cucumber plants per mat $(30 \times 91$ $\times 7.5 \mathrm{~cm}$ ) were planted in May. Output of moisture sensor was measured at interval of each $30 \mathrm{~min}$ for five days after irrigation was stopped. 
マットの水分量が低下するにつれ速くなった。また，給 液停止 5 日後にキュウリがしおれ始めた．この水分セン サの出力值は Fig. 5 で求めたマットの平均飽水度と水 分センサの出力值との関係からみて, マット内の水分量 にほぼ対応して変化した. なお，Fig. 6 で水分センサの 出力值が蒸散の多い日中で小さく, 逆に, 蒸散が少なく なる前夜半に大きくなる傾向が認められた。 また, 給液 が頻繁に行われる日中は，マット内の水分量の不均一分 布も予想されることから，水分センサの信頼性の高い出 力值は, 日中から前夜半を除いた時間带が好ましいと考 えられる。

\section{考察}

ロックウールマットは固相が約 $3 \%$ と小さく，ほぼ液 相と気相の 2 相からなる培地である ${ }^{5)}$. 水分センサは熱 伝導の差からセンサ周辺の水分量を推定するもので, 固 相の小さなロックウールマットでの水分センサの出力值 はほぼ水分量に比例して変化する. 水分量と水分センサ の出力值の関係は Fig. 3 にみられるように逆比例の関 係が成立する. マットの平均飽水度を求めるにはマット の中央部にセンサを設置することが望ましいが，センサ の出力值の精度を保つために， ロークウールマットとつ ねに十分に接触していることが前提となり, 実際栽培で はマット内でのセンサの固定が問題となる.マットの中 でなく上面や下面に水分センサを置く方法はセンサの固 定が容易で, 多少のセンサの移動も出力值に影響しがた い利点がある、マットの上にセンサを置く方法は, 高い 平均飽水度の領域での出力変化が大きくなる長所がある が，マットが一度乾燥しマットの上と下で毛管水が断ち 切られた場合には，その後の出力值がマットの水分量を 反映しない問題がある. 次に, マットの下にセンサを置 く方法は, 高い平均飽水度の領域での出力変化が小さく なるが，過剩水の有無および出力值の経日変化によ り，センサ周辺の水分環境の推移を把握することがで き, 過剩水の防止とマットの平均飽水度の推定が可能で あった。実験に使用した水分センサの出力值でマットの 水分状態を示すと $1.0 \sim 1.4 \mathrm{~V}$ ではマットが完全に過湿 状態, $1.4 \sim 2.0 \mathrm{~V}$ ではマットが飽水状態, $2.0 \sim 2.2 \mathrm{~V}$ で は平均飽水度が約 $80 \% ， 2.2 \sim 2.5 \mathrm{~V}$ では約 $60 \% ， 2.5 \sim$ $2.8 \mathrm{~V}$ では約 $40 \% ， 2.8 \sim 3.4 \mathrm{~V}$ では約 $20 \% ， 3.4 \mathrm{~V}$ 以 上では $20 \%$ 以下となった.

ロックウール栽培では日射量をべースにした給液方法 が基本となっているが7，さらに生育時期や生育ステー ジを考慮した給液管理方法も開発されてきた 11 。 また，
実用場面では，マットの水分状態を毛管連絡の保たれて いる自由水面の高さから検知する方法も用いられてい る. しかしながら, マット内の水分状態を直接, 測定す る実用的な方法はなく, 試作した水分センサはこれに対 応しうる簡易で央用性の高いものである.とくに，マッ 卜の水分状態の変化を, メンテナンスフリーで連続的に 定点計測できることは, 精度の高い培地管理技術を確立 するのに有効である. マットの水分状態は給液量, 水分 センサの出力值および排液量を検知し，これらの值をも とに給液量を調整することで合理的な培地管理が成立す る. また, 以上の水分センサの出力值はすべてコンピュ 一タによる入出力ができ, 自動制御による高精度の培地 管理も可能である.

\section{摘要}

ロックウール栽培の培地管理を安定化させるために, 培地内の水分状態を検知できるセンサを作製し，その実 用性を検討した。

1. 水分センサは一定時間内の二クロム線の加熱によ る温度上昇幅を熱電対で測定し, その大きさにより水分 量を求める方法を用いた. 形状は長さ $50 \mathrm{~mm}$ で $4 \mathrm{~mm}$ 角の棒状の樹脂の中にニクロム線と熱電対を埋め込ん だ.

2. 水分センサの出力值の逆数は, ロックウール培地 の水分量と直線的な関係が成立した。なお，実用的には 培地とセンサとの接触面をつねに安定化させるため, セ ンサをマットの下に設置することが適していた．

3. 培地内の水分状態および水分センサの出力值は, 後夜半から早朝にかけてが安定しており，この時間带で の水分センサの出力値の経日変化から給液量を修正する 方法が培地管理の精度の向上に役立つことを認めた。

\section{文献}

1）青柳光昭. 1990. 「施設園芸における高度化技術の活用」 135-178，全国農業協同組合中央会，東京.

2）佐々木皓二. 1987. 水分センサを用いた給液制御法による 数種固形培地耕. 園学要旨, 昭 62 秋 350-351.

3）菅沼健二・青柳光昭. 1988. ロックウール栽培における給 液管理技術の開発 (第 1 報)。愛知農試研報 20：200-204.

4）田中和夫. 1987. 固形培地新素材およびセンサの開発. 農 及園 62: 111-118.

5）田向和夫・安井秀夫. 1990. 養液栽培用ロックウール培地 の利用. 生物環境調節 28: 165-170.

6)田中和夫・安井秀夫. 1990, 養液栽培用ロックウール 培地 内の養液の移動および排出. 生物環境調節 28: 171-176.

7）安井秀夫. 1986. 固形培地式養液栽培の理論. 農及園 61: 147-159. 